and is reversed by JAK inhibition. Nat Med 2014;20:10431049.

5. Alzolibani AA, Rasheed Z, Bin Saif G, Al-Dhubaibi MS, Al
Robaee AA. Altered expression of intracellular Toll-like receptors in peripheral blood mononuclear cells from patients with alopecia areata. BBA Clin 2016;5:134-142.

\title{
Chronic Exfoliative Cheilitis Successfully Treated by Pinhole Method Using $\mathrm{CO}_{2}$ Laser
}

\author{
Chan Seong Park, Ji-Hye Park, Jongeun Lee, Hyun Jeong Byun, Youngkyoung Lim, Jong Hee Lee, \\ Dong-Youn Lee, Joo-Heung Lee, Jun-Mo Yang
}

Department of Dermatology, Samsung Medical Center, Sungkyunkwan University School of Medicine, Seoul, Korea

\section{Dear Editor:}

Exfoliative cheilitis is an uncommon and chronic inflammatory disorder affecting the vermilion of the lips and characterized by continuous peeling of the vermilion and abnormal production of keratin scales ${ }^{1,2}$. Conventional topical treatment is helpful in some cases but it is not that effective in most cases. Invasive treatment such as peeling with laser, cryosurgery and electrocautery is effective in some cases but it can cause severe discomfort ${ }^{1}$.

A 42-year-old male presented with 4 years of history of chronic thick yellowish hyperkeratotic plaques on both lips. The plaques became thicker and were accompanied by pain and oozing (Fig. 1A). He denied lip licking, biting or rubbing habits. The lesion was resistant to conventional topical treatment such as salicylic acid 10\% ointment and vaseline. He complained that his lips kept getting crusts in spite of conventional treatments. In pathologic examination, it showed nonspecific chronic inflammation with interface dermatitis and lymphoplasmacytic infiltration in the upper dermis (Fig. 2). Based on histopathologic findings, we added the process to diagnosis. Although relatively larger numbers of plasma cells are usually present in the mucosal biopsies and may be non-specific, we checked serum antibodies because secondary syphilis can show
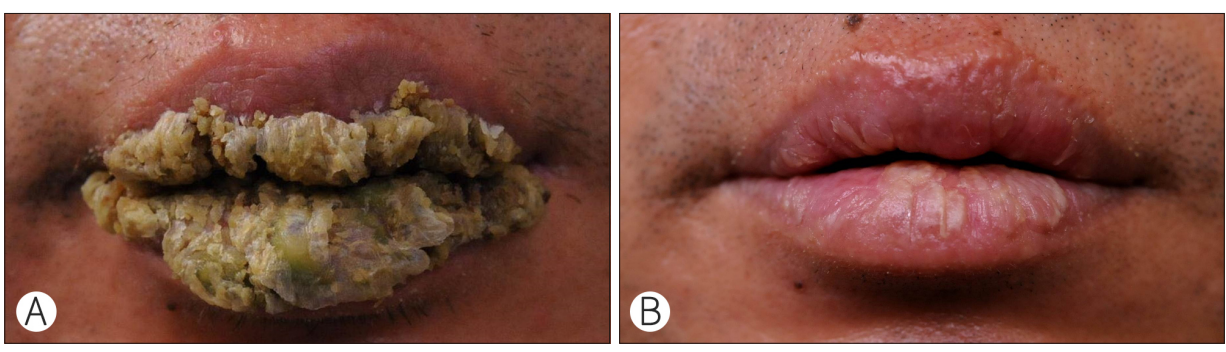

Fig. 1. (A) Highly thick and yellowish plaques on both lips. (B) Almost all of the thick and yellowish hyperkeratotic plaques disappeared after two cycles of treatment. We received the patient's consent form about publishing all photographic materials.

Received April 6, 2018, Revised June 7, 2018, Accepted for publication July 11, 2018

Corresponding author: Ji-Hye Park, Department of Dermatology, Samsung Medical Center, Sungkyunkwan University School of Medicine, 81 Irwon-ro, Gangnam-gu, Seoul 06351, Korea. Tel: 82-2-3410-6578, Fax: 82-2-3410-3869, E-mail: jh1204.park@samsung.com ORCID: https://orcid.org/0000-0002-6699-5202

This is an Open Access article distributed under the terms of the Creative Commons Attribution Non-Commercial License (http://creativecommons.org/ licenses/by-nc/4.0) which permits unrestricted non-commercial use, distribution, and reproduction in any medium, provided the original work is properly cited.

Copyright (C) The Korean Dermatological Association and The Korean Society for Investigative Dermatology 


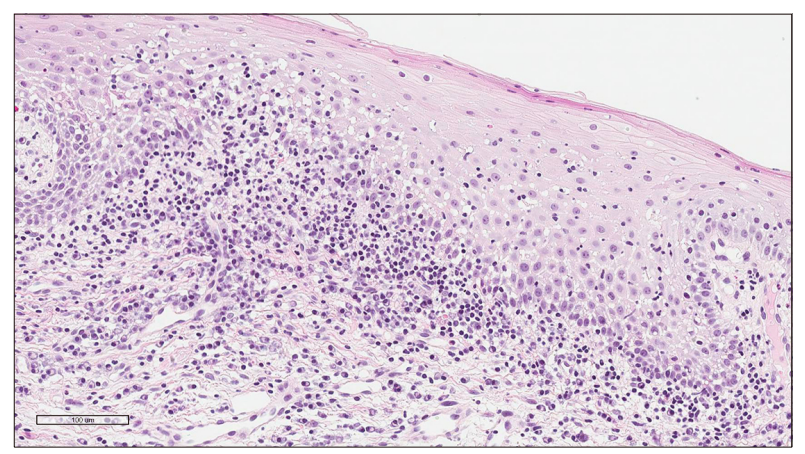

Fig. 2. Interface changes in dermo-epidermal junction and lymphoplasmacytic infiltration in the upper dermis $(H \& E, \times 400)$.

lymphoplasmacytic infiltration and interface change with lichenoid infiltration. The results of serology test such as venereal disease research laboratory (VDRL) was negative. Therefore, considering the nonspecific chronic inflammation on pathology and clinical features, the patient was diagnosed as chronic exfoliative cheilitis. We treated him with pinhole method using $\mathrm{CO}_{2}$ laser after removing the thick plaques which removed easily by gauze rubbing. We made multiple single spot-sized holes at intervals of 1 $\mathrm{mm}$ by using $\mathrm{CO}_{2}$ laser with super-pulse mode, continuous wave and 0.5 to 1 watt. The lesion was almost improved without side effect such as severe pain, discomfort and scar. Almost all of the thick yellowish hyperkeratotic plaques disappeared and he did not feel pain and oozing (Fig. 1B). After three treatment sessions with intervals of 3 months, the lesions remained clear without recurrence for a year. One year later, mild hyperkeratotic scales and Fordyce spots were observed and additional treatment was performed twice with interval of 1 year. There has been no recurrence for 6 months after last treatment. As the treatment session passed, the treatment interval became longer and the symptoms of the patient become milder.

In exfoliative cheilitis, chronic excessive production and subsequent desquamation of a thick keratin scales occur and the patient experiences some degree of discomfort and pain and difficulty in talking, smiling, and eating ${ }^{2}$. There are some treatment options such as conventional topical treatment (keratolytic lip balms, sunscreen, antifungal creams and topical steroids), systemic treatment (antidepressants, antifungal agents, and corticosteroids) and invasive treatment (laser, cryosurgery and electrocautery) ${ }^{1}$. Conventional treatment is helpful in only some cases and invasive treatment usually cause severe pain and discomforts, scarring and delayed wound healing ${ }^{1}$.

Pinhole method using $\mathrm{CO}_{2}$ laser can be used to treat burn scar, anetoderma, syringoma, telangiectasia and etc. ${ }^{3-5}$. In mechanism, thermal stimulation to the surrounding tissues is known to induce neocollagensis and remodeling of the dermal matrix. Also, laser-induced realignment and regeneration of dermal tissues as well as fibrous tissues surround target lesion can improve the skin texture with reduced downtime and adverse events ${ }^{3,4}$. The level of transforming growth factor (TGF)- $\beta 1$ in the fractional $\mathrm{CO}_{2}$ laser-treated areas of skin was significantly increased and TGF- $\beta$ is known to be a potent spur for neocollagenesis and an immunosuppressive cytokine which promotes anti-inflammation. It is presumed that the pinhole method using $\mathrm{CO}_{2}$ laser will be effective in a similar mechanism in chronic exfoliative cheilitis.

In our patient, pinhole method using $\mathrm{CO}_{2}$ laser showed more effective with minimal side effects than conventional treatment. The patient felt minimal pain and discomfort after treatment and showed rapid wound healing without scarring. Also, treatment effects lasted longer. In conclusion, pinhole method using $\mathrm{CO}_{2}$ laser is an effective treatment option for patients with treatment-resistant and chronic exfoliative cheilitis.

\section{CONFLICTS OF INTEREST}

The authors have nothing to disclose.

\section{ORCID}

Chan Seong Park, https://orcid.org/0000-0001-5809-0561

Ji-Hye Park, https://orcid.org/0000-0002-6699-5202

Jongeun Lee, https://orcid.org/0000-0003-1523-2974

Hyun Jeong Byun, https://orcid.org/0000-0002-4354-5655

Youngkyoung Lim, https://orcid.org/0000-0002-6409-2704

Jong Hee Lee, https://orcid.org/0000-0001-8536-1179

Dong-Youn Lee, https://orcid.org/0000-0003-0765-9812

Joo-Heung Lee, https://orcid.org/0000-0002-1121-2055

Jun-Mo Yang, https://orcid.org/0000-0003-0656-8046

\section{REFERENCES}

1. Almazrooa SA, Woo SB, Mawardi H, Treister N. Characterization and management of exfoliative cheilitis: a singlecenter experience. Oral Surg Oral Med Oral Pathol Oral Radiol 2013;116:e485-e489.

2. Mani SA, Shareef BT. Exfoliative cheilitis: report of a case. J Can Dent Assoc 2007;73:629-632.

3. Lee SJ, Yeo IK, Kang JM, Chung WS, Kim YK, Kim BJ, et al. Treatment of hypertrophic burn scars by combination lasercision and pinhole method using a carbon dioxide laser. Lasers Surg Med 2014;46:380-384.

4. Lee SJ, Goo B, Choi MJ, Oh SH, Chung WS, Cho SB. 
Treatment of periorbital syringoma by the pinhole method using a carbon dioxide laser in 29 Asian patients. J Cosmet Laser Ther 2015;17:273-276.

5. Chung BY, Han SS, Moon HR, Lee MW, Chang SE.
Treatment with the pinhole technique using erbium-doped yttrium aluminium garnet laser for a café au lait macule and carbon dioxide laser for facial telangiectasia. Ann Dermatol 2014;26:657-659. 